\title{
Developmental dyslexia in an orthography of intermediate depth: the case of European Portuguese
}

\author{
Ana Sucena • São Luís Castro • Philip Seymour
}

Published online: 6 January 2009

(C) Springer Science+Business Media B.V. 2009

\begin{abstract}
Fifteen Portuguese children with dyslexia, aged 9-11 years, were compared with reading and chronological age controls with respect to five indicators related to the phonological deficit hypothesis: the effects of lexicality, regularity, and length, implicit and explicit phonological awareness, and rapid naming. The comparison between groups indicates that Portuguese children with dyslexia have a phonological impairment which is revealed by a developmental deficit in implicit phonological awareness and irregular word reading (where younger reading level controls performed better than dyslexics) and by a developmental delay in decoding ability and explicit phonological awareness (where dyslexics matched reading level controls). These results are discussed in relation to the idea that European Portuguese is written in an orthography of intermediate depth.
\end{abstract}

Keywords Developmental dyslexia $\cdot$ Portuguese $\cdot$ Phonological deficit

\section{Introduction}

Portuguese is commonly regarded as a relatively shallow orthography. As such, it might be expected that studies of reading development and dyslexia in Portuguese would yield results similar to those found in other shallow orthographies. However,

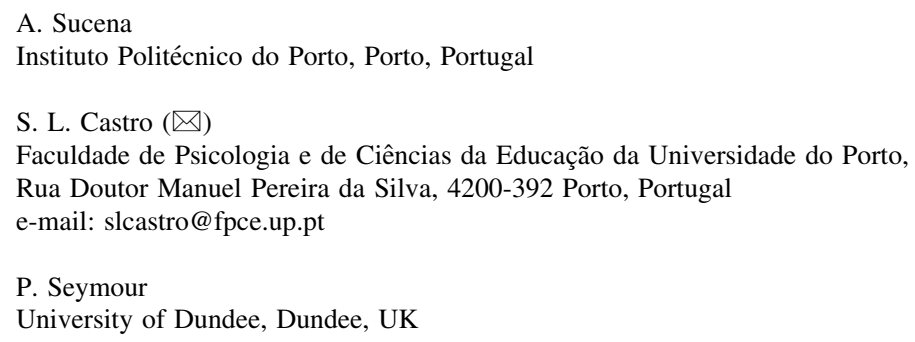


Table 1 Vocalic grapheme to phoneme conversions in Portuguese

\begin{tabular}{|c|c|c|c|c|}
\hline Letter & Phoneme & Orthography & Phonology & Translation \\
\hline \multirow[t]{3}{*}{$\mathrm{a}$} & $\mathrm{a}$ & casa & $' k a z \alpha$ & house \\
\hline & $\alpha$ & cada & $' \operatorname{kad} \alpha$ & each \\
\hline & $\tilde{\alpha}$ & andar & $\tilde{\alpha}^{\prime}$ dar & to walk \\
\hline \multirow[t]{6}{*}{$\mathrm{e}$} & $\varepsilon$ & nesta & 'ne $\int \mathrm{t} \alpha$ & in this one \\
\hline & $\mathrm{e}$ & cesta & 'se $\int \mathrm{t} \alpha$ & basket \\
\hline & $\mathrm{i}$ & elevador & iləv $\alpha$ 'dor & elevator \\
\hline & ә & melão & mə'l $\tilde{\alpha} w$ & to be \\
\hline & $\alpha$ & coelho & ku' $\alpha \lambda \mathrm{u}$ & rabbit \\
\hline & $\tilde{\mathrm{e}}$ & embora & ẽ'bor $\alpha$ & although \\
\hline \multirow[t]{3}{*}{ i } & $\mathrm{i}$ & igreja & i'gr $\alpha j \alpha$ & church \\
\hline & $\tilde{\mathbf{1}}$ & vinco & ’vĩku & crease \\
\hline & ә & ministro & mə'ni tru & minister \\
\hline \multirow[t]{4}{*}{ o } & ó & mola & 'mól $\alpha$ & peg \\
\hline & o & molho & 'mo $\lambda u$ & sauce \\
\hline & $\mathrm{u}$ & molhar & mu' $\lambda$ ar & to wet \\
\hline & $\tilde{\mathrm{o}}$ & monte & 'mõtə & hill \\
\hline \multirow[t]{2}{*}{$\mathrm{u}$} & $\mathrm{u}$ & uva & 'uv $\alpha$ & grape \\
\hline & $\tilde{\mathrm{u}}$ & um & $\tilde{\mathrm{u}}$ & one \\
\hline
\end{tabular}

the cross-language study of beginning reading by Seymour, Aro and Erskine (2003) suggested that learning to read in Portuguese proceeded less rapidly than in shallow orthographies such as German, Greek, Italian or Finnish. At the end of first grade children in most orthographies (9 out of 13) read words and nonwords with near ceiling results. In sharp contrast, English children exhibited poor reading results for both words and nonwords (respectively, 34\% and 29\%). The results for Portuguese children lay between the near ceiling results from shallow orthographies and the poor results for English. Portuguese children read $75 \%$ of words and nonwords, a result close to the findings for French and Danish $(79 \%$ and $71 \%$ for words, and $85 \%$ for nonwords).

Several orthographic and phonetic features concur to characterize Portuguese as an orthography of intermediate depth. Vocalic GPCs pose a special difficulty, as there are only five vowel letters for 18 vocalic phonemes. Table 1 sets out the vowel letters and corresponding phonemes in Portuguese. We can see that, for the letter " $u$ ", there are only two possible corresponding phonemes, non-nasal and nasal, indicated by the adjacent letters " $m$ " or " $n$ ", an orthographic rule that is common to all the five vowel letters. But, in order to know whether to nasalize the vowel or not, the reader must check if those letters are in the same syllable as the vowel or in the following syllable. For example, um and uma ("one" for masculine and feminine grammatical genders, respectively) are $\mathrm{read} / \tilde{\mathrm{u}} / \mathrm{and} / \mathrm{um} \alpha /$, because in the first case the nasal consonant belongs to the same syllable as the vowel, whereas in the second it is part of the following syllable $(u-m a)$.

Syllabic division should, on the face of it, be an easy task for Portuguese children, given that Portuguese is a Romance language with a predominance of CV 
syllables (Vigário \& Falé, 1994). However, syllabic boundaries are in fact not very clear due to another feature of spoken European Portuguese: vocalic reduction. In oral language, many vowels are not pronounced, so that the noun Rodrigo is pronounced [ru'drig], dropping the final [u] or even two as in [rdrig] (in rapid speech). It follows that GPCs are not straightforward for Portuguese children, as they are being asked to identify vowels which they do not always pronounce and to make syllabic divisions which are not present in speech. For example, in almost all words ending in "e" or in "o", this final vowel is suppressed in fluent speech so that the orthographic bisyllable leite, milk, is a phonological monosyllable, [layt]. It is worth mentioning that none of the cases exemplified above occur in Brazilian Portuguese, because vocalic reduction is not so prevalent there; on the contrary, vowels are typically pronounced clearly and without reduction. The extreme case is of the final "e", that is mute in Portugal, and is pronounced [1] in Brazil.

So far, we have focused on the vowel "u", and discussed orthographic rules that children have to attend in order to read that letter correctly. For the remaining vowel letters, there are more than two possible phonemes to choose from and also fewer rules underlying the correspondences. To illustrate, in casa, house, the first "a" is read [a] but the second is read [ $\alpha$ ], whereas in cada, each, both letters "a" are read $[\alpha]$. Some vocalic GPCs obey contextual rules, such as the conversion of "o" at the end of a word to [u] (e.g. gato, cat, as ['gatŭ]), but many conversions are irregular and present obstacles to the development of the decoding process. Many words will be read inaccurately if they are decoded grapheme by grapheme, instead they need to be recognized using larger orthographic patterns or whole words. There are also complexities affecting consonantal GPCs. These include complex graphemes (e.g. "lh" corresponds to $[\lambda]$ ) and contextual regularities (e.g., "s" corresponds to [S] at the end of word or syllable, to [s] at the beginning of the word, and to $[\mathrm{z}]$ in the intervocalic position).

These linguistic features support the suggestion that European Portuguese is an orthography of intermediate depth. Our aim in this paper is to undertake a preliminary examination of the nature of developmental dyslexia (reading difficulty) in Portuguese. We keep the distinction between European and Brazilian Portuguese throughout the paper and will focus on the European variant because the salient differences in pronounciation between both dialects impact on the transparency of the correspondences between print and speech. Besides, some differences in the orthographic conventions of the two dialects concur to the greater transparency of Brazilian Portuguese; these concern mute consonants and the use of diacritics. Whereas in European Portuguese "c", "p", and "t" are sometimes mute, in Brazilian Portuguese they are omitted in such cases (Egipto and Egito for Egypt, respectively); also, in this variant diacritics are used to disambiguate between alternative pronounciations of words that, in European Portuguese, are irregular due precisely to the lack of diacritic (respectively, tranquïlo and tranquilo, tranquil, both

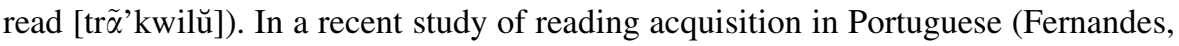
Ventura, Querido, \& Morais, 2007), for similar reasons the authors also chose to refer specifically to European Portuguese (the study was conducted in Portugal).

A key question is whether dyslexia in an intermediate orthography might be expected to conform to the pattern shown by a deep orthography, such as English, or 
to the one for shallow orthographies, such as German, or to some kind of intermediate pattern. Seymour et al. argued that there was a threshold level of orthographic complexity which induced a switch from a single foundation mode of learning to read (as found in shallow orthographies) to a dual foundation mode with distinct mechanisms for word recognition and decoding. Portuguese was supposed to lie above this threshold. This implies that dyslexia in Portuguese should conform more to the English model than to the German model. However, Seymour et al. found that lexicality effects were in general smaller or reversed in Romance 'simple syllable' languages (Portuguese included) as opposed to Germanic languages. It is thus not clear which pattern suits Portuguese dyslexic children better, the German model with high dysfluency and minor accuracy failures in nonword reading, or the English model with low accuracy for nonword reading.

Much previous research about developmental dyslexia has been conducted in the English language, and studies of reading processes have concentrated on psycholinguistic effects of variables such as word frequency, orthographic consistency and regularity, word length, and lexicality. The results from these studies have shown that dyslexic children have a special disadvantage in reading nonwords as compared to words - a lexicality effect_-and/or special difficulties with reading irregular as compared to orthographically regular words - a regularity effect (e.g. Coltheart, Masterson, Byng, Prior, \& Riddoch, 1983; Frith, 1985; Rack, Snowling, \& Olson, 1992; Seymour \& Evans, 1999; Seymour \& McGregor, 1984; Snowling, 2000; Wagner \& Torgesen, 1987). According to the dual route theory (e.g. Castles \& Coltheart, 1993), lexicality and regularity effects may be independent, giving rise to a phonological pattern (special difficulty with nonwords) or a surface pattern (special difficulty with irregular words). Developmental phonological dyslexia would reflect an impairment in the sublexical reading route that co-exists with a normal development of the lexical reading route, so that nonwords are read worse and more slowly than words. Surface dyslexics would develop sublexical reading strategies better than lexical ones, explaining better results for nonwords than for irregular words. Evidence supporting the distinction between these two profiles has been reported for English (e.g., Manis, Seidenberg, Doi, McBride-Chang, \& Peterson, 1996; Seymour \& Evans, 1999) and for French (Genard, Mousty, Alegria, Leybaert, \& Morais, 1998). However, consistent with connectionist approaches to reading (Harm \& Seidenberg, 1999; Zorzi, Houghton, \& Butterworth, 1998) other researchers dispute this view proposing instead that the results can best be explained by assuming one profile only, developmental phonological dyslexia (SprengerCharolles, Colé, Lacert, \& Serniclaes, 2000; Stanovich, Siegel, \& Gottardo, 1997).

The discussion on the existence of one or two dyslexia profiles has at its core the issue of the independence, or not, of phonological and lexical processes. Whereas the dual route theory proposes that they are independent, alternative accounts sustain that phonological processes are primary, lexical processes being subsidiary (Share, 1995, 1999; Stanovich et al., 1997). According to Share, an intact development of lexical reading together with an impairment of phonological processes is implausible, because lexical reading is built upon phonology; indeed, he argues, the results from most studies fail to show evidence of children with a severe decoding deficit accompanied by a normal development of the lexical 
processes. (However, see the individual case studies reported by Seymour and Bunce (1994) and Evans and Seymour (1997) for evidence that this dissociation may occur in some special instances). On the other hand, Castles and Coltheart (1993) claim to have demonstrated the existence of the opposing pattern in eight cases of pure surface dyslexia, a situation that is problematic for the unitary model. Still, Stanovich et al. (1997) and Sprenger-Charolles et al. (2000) argue that the surface dyslexia profile disappears if dyslexic children are compared with reading level controls instead of with chronological age controls. In the same vein, Ziegler and Goswami (2005, p. 20) state that "dyslexic children are not worse than RL [reading level] children in gaining orthographic access to whole words. Rather, they are worse at computing sublexical phonology, even in languages such as Korean, German".

Whether or not different profiles of developmental dyslexia are an important feature of reading impairment can be elucidated by comparing dyslexia in different alphabetic orthographies which vary in depth (Frost, Katz, \& Bentin, 1987; Katz \& Frost, 1992). According to the orthographic depth hypothesis, readers in a shallow, consistent orthography rely predominantly on the phonological route (which suffices for correct reading), while in an inconsistent, deep orthography, readers rely mainly on the lexical route and to a lesser extent on the phonological route (which does not always allow for correct reading). This hypothesis leads to the possibility that outcomes for more shallow orthographies may differ from those found for English. Indeed, findings for German, Dutch, and Italian lend support to this view. A lack of lexicality or regularity effects on accuracy has been reported, dyslexia being characterized mainly by dysfluency and large length effects (for German: Wimmer, 1993; for Dutch: Yap \& van der Leij, 1993; for Italian: Zoccoloti et al., 1999). For example, studies with German dyslexic children have shown that the lexicality effect on accuracy is significant only at the 1st grade (Wimmer, 1993, 1996). Landerl, Wimmer, and Frith (1997) compared German and English dyslexics reading high- and low-frequency words. They argued that high-frequency words could be read through a lexical process resulting in a "fast automatic word recognition", whereas rare words would probably be read by sequential graphemeto-phoneme conversion. Low accuracy or long reaction times for high-frequency words would indicate a deficit in the lexical process while low frequency word reading would provide a measure of the efficiency of phonological processes. The results showed that German dyslexic children read high- and low-frequency words equally well. This was taken to indicate that dyslexia in German does not prevent the development of good decoding abilities.

In the light of this background, we aimed to investigate dyslexia in Portuguese by carrying out studies of reading accuracy and speed in relation to variables of lexicality, orthographic regularity, and length. We also examined measures of phonological awareness and rapid sequential naming as these tasks are well known to be related to reading and dyslexia. The results for Portuguese children with dyslexia were compared with age matched controls and reading level controls. If differences between dyslexics and controls occurred only in relation to the chronological control group, this would reveal a developmental delay; if they occurred in relation to the reading level control group, this would suggest a core 
developmental deficit. These possibilities were examined in relation to five established indicators of phonological processing:

1. The lexicality effect is defined as better reading of words than of nonwords. A phonological decoding deficit is indicated by a stronger lexicality effect for dyslexics than for controls. It is pertinent to establish whether the deficit is expressed in accuracy, as in deep orthographies such as English, or in reaction times, as in transparent orthographies such as German.

2. The orthographic regularity effect is the better reading of regular words than of irregular ones. It is an indicator of development of the lexicon: the more developed the orthographic lexicon is, the smaller the regularity effect will be, and vice-versa. As previously described, recent research with German-speaking dyslexic children reveals that phonological deficits do not produce a lexicality effect but instead prevent children from developing an orthographic lexicon, as expressed by the regularity effect (Wimmer, Mayringer, \& Landerl, 2000).

3. The syllable length effect is the better reading of shorter words than longer ones. This effect is treated as an indicator of reliance on sequential decoding. Previous results have varied. Landerl et al. (1997) reported no difference between German dyslexics and controls in reading times for shorter and longer words, although the difference was significant for English dyslexics and controls. On the other hand, Ziegler et al. (2003), using reaction time measures, found a marked effect of length for German as well as for English dyslexics as compared to controls.

4. Phonological awareness tasks are indicators of the capacity for internal manipulation of speech segments. Landerl et al. (1997) compared phonological awareness in English and German dyslexic children and found similar levels of performance, despite large differences in reading accuracy: "The German dyslexic children considered this task almost as difficult as the English dyslexic children" (p. 327).

5. Rapid naming tasks require children to recode symbols into speech and are viewed as a measure of the efficiency of phonological recoding in lexical access. Dyslexic children and adults are slower than normal readers on rapid naming tasks (Denckla \& Rudel, 1976; Vellutino, Scanlon, \& Spearing, 1995) and early differences in rapid naming tasks predict reading difficulties (Lyytinen et al., 2006; Wolf, Bally, \& Morris, 1986), and may reflect different contributory skills other than those related to phonological awareness (Bowers \& Wolf, 1993; Cardoso-Martins \& Pennington, 2001).

\section{Method}

Reading measure and participant pre-selection

At the time the study was conducted, and to the best of our knowledge, there were no standardized tests for the assessment of reading skills and developmental dyslexia for Portuguese school age children. Consequently, we developed the 
procedure described below in order to find the specifically reading impaired children that were then asked to participate in this study.

First, in order to have an external measure of reading difficulty that was independent from the teachers' judgement, we adapted Lobrot L3, a French reading test (Lobrot, 1973). The Portuguese adaptation of Lobrot L3 was administered to 470 Portuguese native speakers, attending the second $(n=127)$, third $(n=133)$, fourth $(n=125)$, and fifth $(n=85)$ grades for the first time (Sucena \& Castro, 2008). This test requires accurate and fluent decoding, as well as basic comprehension skills. It consists of reading sentences where the final word is missing and to choose which word, from a set of five alternatives, is a valid completion. Each five-word set includes the target word and four distractors, each of a different type: either no resemblance to the target word, or a visual, phonological or semantic resemblance. Thus a correct answer is likely to implicate a precise decoding of the alternatives. The position of the target and distractor words varies pseudorandomly across sentences. There are 36 sentences and a time limit of $5 \mathrm{~min}$. We used this test as a screening tool for the detection of reading impaired children. The criterion to define impaired reading was set to $-1.5 \mathrm{SD}$ relative to the mean of the normative sample of the same grade; this is more stringent than the $-1 \mathrm{SD}$ that is sometimes used (e.g., Sprenger-Charolles, Colé, Béchennec, \& Kipffer-Piquard, 2006), but open enough to probably include mild to moderate cases of reading impairment.

Then, children were selected to participate in this study according to the following criteria: scoring 1.5 SD below the grade appropriate mean on the Portuguese adaptation of the Lobrot test of reading level; having no known additional learning or spoken language problems, according to the teachers' and parents' reports; scoring at age-appropriate average or above average level in the Ravens Coloured Progressive Matrices, a test for which Portuguese norms were available (Simões, 2000); and being of average socio-economic background. These criteria were designed to exclude extrinsic reasons that might account for, or be associated with, impaired reading, such as a known history of learning or language problems, an underprivileged milieu, and/or intellectual limitations (as assessed by the Raven Coloured Progressive Matrices). Children fulfilling these criteria were considered specifically reading impaired or dyslexic.

\section{Participants}

Fifteen children with dyslexia, selected as described above, participated in this study. They were all native speakers of Portuguese and attended public schools on the third and fourth grades. They were tested in the last trimester of the academic year. It should be mentioned that these children were not attending special tuition classes for dyslexics, as these were not part of the public school curriculum.

Dyslexic children were compared with two control groups: reading level controls, who were second and third graders $(n=49)$, and chronological age controls, who were fourth graders $(n=25)$. These children came from the same or similar public schools as the reading impaired ones. The characteristics of the three groups are given in Table 2. All children had been instructed on a mixed teaching method, which is the most widely used in Portuguese public schools. Informed 
Table 2 Mean age and scores on the reading level test (percent correct and $Z$ scores) for children with dyslexia and controls

\begin{tabular}{llllll}
\hline & $N$ & Age (SD) & Range & $\begin{array}{l}\text { Reading } \% \\
\text { Min-Max }\end{array}$ & $\begin{array}{l}\text { Reading Z scores } \\
\text { Mean, Min-Max }\end{array}$ \\
\hline Dyslexia group & 15 & $9 ; 9(0.47)$ & $9 ; 1-10 ; 8$ & $30-67$ & $-1.72,-2.57$ to -1.30 \\
Reading controls & 49 & $8 ; 3(0.6)$ & $7 ; 3-9 ; 3$ & $30-67$ & $0.12,-1.05$ to 1.89 \\
Chronological controls & 25 & $9 ; 8(0.3)$ & $9 ; 3-10 ; 3$ & $69-100$ & $0.18,-1.13$ to 1.22 \\
\hline
\end{tabular}

consent was obtained from parents and school authorities before starting data collection.

\section{Word and nonword lists}

For the reading aloud tasks we selected a set of 72 content words that varied according to orthography (regular versus irregular words) and to length (with 2, 3 or 4 syllables). Nonwords were derived from those words by changing one or two letters; all the criteria established for words were kept in the nonwords, including the critical segment that defined the orthographic condition.

Words were selected according to the most salient characteristics of the Portuguese lexicon with respect to orthographic syllable length and to stress assignment, as described by Gomes in her analysis of the Portuguese lexical database Porlex (Gomes, 2001; Gomes \& Castro, 2003). Multisyllabic words account for about $99 \%$ of the Portuguese lexicon; of these, 3-syllable words are the most common $(33 \%)$, followed by $4-(30 \%)$ and 2 -syllable words $(16 \%)$. We selected 2-, 3- and 4-syllable words, 24 of each type; the number of letters, graphemes and phonemes was kept constant in each length. The majority of Portuguese words are stressed in the penultimate syllable $(59 \% ; 34 \%$ in the last syllable, and $6 \%$ in the antepenultimate syllable), and among these diacritics are not very common (only $13 \%$ have it). Thus, we selected words that were stressed on the penultimate syllable and had no diacritic. As the CV syllable structure is the most frequent in Portuguese, $96 \%$ of the words we selected are composed of CV syllables; the remaining $4 \%$ also included CCV and CVC syllables. Furthermore, we chose words of intermediate frequency according to Corlex frequency database (Bacelar do Nascimento et al., 2005).

The word sets were divided between: (1) orthographically regular words and (2) orthographically irregular words. Orthographically irregular words included one irregular grapheme-to-phoneme mapping while the remaining mappings were regular. Table 3 describes the irregular GPCs selected for this study with words exemplifying each irregularity.

\section{Phonological awareness}

Phonological awareness was tested for three linguistic units, syllable, phoneme and rime, in two different tasks: the same-different task (Treiman \& Zukowski, 1991) and the common unit task (Duncan, Seymour, \& Hill, 1997). Stimuli were disyllabic 
Table 3 Examples of irregular words and corresponding GPCs

\begin{tabular}{|c|c|c|c|c|c|}
\hline \multicolumn{5}{|c|}{ Portuguese irregular words } & \multirow{2}{*}{$\frac{\text { Irregular GPCs }}{<\mathrm{ct}\rangle}$} \\
\hline Orthography & tecto & facto & & & \\
\hline Phonology & 'tetu & 'faktu & & & $/ \mathrm{t} / \mathrm{kt} /$ \\
\hline Translation & ceiling & fact & & & \\
\hline Orthography & adoptivo & apto & & & $<\mathrm{pt}>$ \\
\hline Phonology & ado'tivo & 'aptu & & & $/ \mathrm{t} / / \mathrm{pt} /$ \\
\hline Translation & great & able & & & \\
\hline Orthography & pior & inferior & maioria & & $<$ ior $>$ \\
\hline Phonology & pjor & ĩfə'rior & maju'ri $\alpha$ & & /jór/ /jôr/ /jur/ \\
\hline Translation & worse & inferior & majority & & \\
\hline Orthography & fixo & existir & auxiliar & taxa & $\mathrm{V} \times \mathrm{V}$ \\
\hline Phonology & fiksu & iž̌s’tir & awsi'ljar & $\operatorname{ta} \int \alpha$ & $/ \mathrm{ks} / / \mathrm{z} / / \mathrm{s} / / \mathrm{S} /$ \\
\hline Translation & fixed & to exist & to help & $\operatorname{tax}$ & \\
\hline
\end{tabular}

Note: In Brazilian Portuguese, tecto is spelled teto; facto is pronounced /fatu/ and spelled fato

words stressed on the first syllable, and the critical segment was always in the first syllable. In the same-different task, the child had to judge whether a pair of words shared a segment, or not (e.g., in rude-rumo, rough-course, the initial syllable is identical; in tosse-vaso, cough-vase, no phones are shared). In the common unit task the child was asked to pronounce the shared segment (e.g., for the rime in the pair bolso-polpa, pocket-pulp, the response should be [ol]). The complete list of stimuli can be inspected in the Appendix.

\section{Rapid naming}

Rapid naming tasks may include objects, colours or other symbols. We used the four basic colours (red, green, yellow and blue) in order to ensure that the children would be well familiarized with the stimuli and corresponding words. We created an image composed of $16(4 \times 4)$ pseudorandomly distributed coloured squares, each square in one of the colours, against a black background. A $2 \times 2$ square was created for the training trial.

\section{Procedure}

In the reading tasks, four lists of 18 items each were presented: two lists of words $(n=16 \times 2)$ and two lists of nonwords $(n=16 \times 2)$, each composed of items with two, three or four syllables. Lists were administered with the Cognitive Workshop software, which allows accuracy coding and on-line recording of responses and reaction times. The items were shown on a laptop Lifebook C Fujitsu computer at a comfortable viewing distance; they appeared in Times New Roman font, size 48. After a 1,000 ms warning signal (an asterisk) followed by a 1,000 ms delay, the stimulus was presented on the screen for up to $10 \mathrm{~s}$. Participants were required to 
read each stimulus as quickly and accurately as possible. Responses were recorded on-line into a digital sound file, and scored manually for accuracy. RTs were automatically calculated from the start of stimulus presentation until the onset of the response, and then checked off-line by inspecting the digital sound file; if necessary, the markers of the beginning of the response were manually adjusted so that artifacts due to extraneous noise or coughs were eliminated. Only the RTs of correct responses were used in further analyses.

The phonological awareness tasks were administered orally and blocked by task type (same-different, common unit) and linguistic unit (syllable, phoneme and rime), resulting in six sessions distributed across different days. The same-different task was applied first. Children were told there was a clown who liked hearing the same bits of sound, and they were asked to point to the "happy clown" if they heard "similar bits of sounds" and to the "sad clown" if they did not. The common unit task was tested in the three last sessions. Children were told that "now the clown is always happy because there will always be equal bits of sound", and they were asked to pronounce the shared segment. They were forewarned that the "similar bits would be towards the initial part of the word, not in the end".

In the rapid naming task, the visual $4 \times 4$ grid containing primary colours was presented for $30 \mathrm{~s}$. The child was asked to name the colours consecutively, left to right from top to bottom. Vocal responses were recorded via a microphone. The number of correct namings within $30 \mathrm{~s}$ was registered for each child.

Each child was tested individually. Children were asked to participate in a "words and pictures game" and were assured that the tasks were not part of a school exam. Before each task children were introduced with practice trials, and all sessions were run in a quiet room.

\section{Results}

We conducted Anovas in order to determine whether there were significant differences between the dyslexic group and the reading level and chronological age control groups with respect to each of the five indicators of phonological processing. Given that the age in the dyslexic group varied from 9 to 11 years, in order to ensure that the comparisons with chronological controls were not biased by age, Ancovas with Group as a factor and Age as a covariate were also calculated.

\section{Lexicality effect}

Table 4 shows average accuracy and reaction times for the total set of words (regular and irregular) and separately for irregular words, regular words and regular nonwords. The subtraction of regular word performance from nonwords (lexicality effect) expresses the magnitude of the decoding deficit. A preliminary Anova showed a significant effect of lexicality, for both accuracy $(F[1,88]=53.34$, $p<.001)$ and reaction times $(F[1,88]=9.18, p=.003)$ : words were read better and faster than nonwords. Ancovas with Age as a covariate and Group (dyslexic 
Table 4 Mean percent of correct responses and reaction times for dyslexics, reading level controls and chronological age controls

\begin{tabular}{llll}
\hline & Dyslexics & RL controls & CA controls \\
\hline Accuracy & & & \\
Words (regular and irregular) & 79.9 & 87.1 & 93.8 \\
Irregular Words (IrregW) & 46.2 & 68.3 & 83.1 \\
Regular Words (RegW) & 91.8 & 93.4 & 97.3 \\
Nonwords (NonW) & 81.5 & 84.6 & 90.7 \\
Lexicality effect & & & \\
$\quad$ RegW-NonW & $10.3^{* *}$ & $8.8^{* *}$ & $6.6^{* *}$ \\
$\quad$ & -1.5 & $-3.7^{* *}$ \\
$\quad$ Dyslexics-RL, Dyslexics-CA & & & $14.2^{* *}$ \\
Regularity effect & $45.6^{* *}$ & $25.1^{* *}$ & $31.4^{* *}$ \\
$\quad$ & & $20.5^{* *}$ & \\
$\quad$ RegW-IrregW & & & 1,207 \\
$\quad$ Dyslexics-RL, Dyslexics-CA & 1,685 & 1,487 & 1,340 \\
Words (regular and irregular) & 2,057 & 1,598 & 1,163 \\
Irregular Words (IrregW) & 1,561 & 1,450 & 1,364 \\
Regular Words (RegW) & 1,772 & 1,710 & \\
Nonwords (NonW) & & & -201 \\
Lexicality effect & -211 & $-259^{* *}$ & $-10^{*}$ \\
$\quad$ RegW-NonW & & -48 & $177^{* *}$ \\
$\quad$ Dyslexics-RL, Dyslexics-CA & & & $319^{* *}$ \\
Regularity effect & & & \\
$\quad$ RegW-IrregW & $496^{* *}$ & & \\
$\quad$ Dyslexics-RC, Dyslexics-CA & & & \\
\hline
\end{tabular}

* Marginal effect $(p=.06)$

** Significant effect $(p<.05)$

versus chronological controls) as factor showed that neither Age nor the interaction of Age $\times$ Group reached significance, neither for accuracy (for regular words, respectively: $F[1,38]=1.22$, ns; $F[1,38]=2.49$, ns; for nonwords: both $F<1$ ) nor for reaction times (for regular words, respectively: $F[1,38]=3.86$, ns; $F<1$; for nonwords: $F[1,38]=1.31$, ns; $F[1,38]=1.27$, ns). Due to the absence of an effect of age or its interaction with group, we now report the results on the effect of lexicality for the three groups. Anovas of the accuracy data revealed that the lexicality effect was significant for the dyslexic group $(10 \%$ advantage; $F[1,14]=11.62, p<.005)$, as well as for the chronological $(9 \% ; F[1,24]=12.72, p<.002)$ and reading level controls $(7 \% ; F[1,48]=28.80, p<.001)$. In reaction times, the lexicality effect was significant for the reading level controls $(F[1,48]=11.84, p<.001)$ but not for the other groups, (both $F<1$ ). Subsidiary analyses established that the dyslexics' results were inferior to the chronological age controls' for accuracy only $(F[1,38]=10.49$, $p<.003$; for reaction times, ns) but equivalent to those of the reading level controls $(F<1$, both for accuracy and reaction times). 


\section{Regularity effect}

Regularity had strong effects on accuracy and reaction times in the three groups (see Table 4). Ancovas run on accuracy for irregular words, with Age as a covariate and Group (dyslexics versus chronological controls) as a factor, indicated that Age was not significant $(F[1,38]=3.92$, ns $)$, but its interaction with Group was $(F[1,38]=9.358, p<.005)$, reflecting the fact that younger dyslexics had extremely low results in comparison with the chronological controls. However, the results of similar Ancovas on reaction times revealed that neither age nor the interaction reached significance $(F[1,38]=2.02$, ns; $F[1,38]=1.97$, ns). These results, combined with the fact that chronological controls read regular word at the ceiling level ( $97 \%$ correct), lead us to focus on reaction times for the comparison with chronological age controls. Nevertheless, we describe the results of the Anovas on accuracy because they closely match those of the reaction times.

Repeated measures Anovas contrasting dyslexics and chronological age controls revealed significant effects for Group (RTs: $F[1,38]=5.37, p<.03$; accuracy: $F[1,38]=28.0, p<.001)$, Regularity (RTs: $F[1,38]=22.85, p<.031$ accuracy: $F[1,38]=64.27 ; p<.001$ ), as well as the interaction (RTs: $F[1,38]=4.84, p<.04$; accuracy: $F[1,38]=18.17, p<.001)$. The interaction was due to the fact that the effect of regularity was stronger for dyslexic children $(46 \%$ and almost $500 \mathrm{~ms}$ advantage of regular words) than for same age controls (14\%, $177 \mathrm{~ms})$. The comparison between the dyslexic group and the reading age controls yielded significant effects for Regularity (accuracy: $F[1,62]=115.12, p<.001$; RTs: $F[1,62]=15.52, p<.001)$, and for the interaction of Group with Regularity (accuracy: $F[1,62]=9.47, p<.004$; RTs: $F[1,62]=4.36, p<.04$ ). The Group effect was significant for accuracy $(F[1,62]=7.24, p<.001)$, but not for reaction times $(F<1)$. The interaction is explained by the fact that the results for the regular words were, on average, similar in dyslexics (92\% correct, 1,560 ms RT) and reading level controls (93\% correct, 1,450 ms RT), but differed substantially for the irregular words, where the younger controls $(68 \%, 1,598 \mathrm{~ms})$ performed better than the dyslexic children $(46 \%, 2,057 \mathrm{~ms})$. In short, the effect of regularity was stronger for dyslexic children $(46 \%, 496 \mathrm{~ms})$ than for younger reading level controls $(25 \%$, $148 \mathrm{~ms})$.

\section{Length effect}

Reaction times for regular words and nonwords with a different number of syllables can be inspected on Table 5 (accuracy did not vary according to length). Preliminary Anovas showed that length was significant for all groups, 2-syllable items being read significantly faster than 3- and 4-syllable items: for dyslexic children, $F[2,26]=6.45, p<.005$, for reading level controls, $F[2,96]=35.79, p<.001$, and for chronological age controls $F[1,48]=20.04, p<.001$.

Ancovas with Group as factor and Age as covariate, run separately for regular words and for nonwords in each of the three lengths showed that neither Age nor its interaction with Group reached significance with one exception: Age reached significance for 2 -syllable regular words $(F[1,38]=6.85, p<.05)$. However, since 
Table 5 Mean reaction times for dyslexics, reading level controls and chronological age controls, for regular words and nonwords split by syllable length

\begin{tabular}{|c|c|c|c|c|c|c|}
\hline & \multicolumn{3}{|c|}{ Regular words } & \multicolumn{3}{|l|}{ Nonwords } \\
\hline & Dyslexics & RL & $\mathrm{CA}$ & Dyslexics & RL & $\mathrm{CA}$ \\
\hline 2-Syllables & 1,182 & 968 & 433 & 1,491 & 1,332 & 1,044 \\
\hline 3-Syllables & 1,704 & 1,214 & 1,108 & 1,708 & 1,748 & 1,412 \\
\hline 4-Syllables & 1,796 & 1,306 & 1,220 & 2,117 & 1,636 & 1,387 \\
\hline Length effect ${ }^{\mathrm{a}}$ & $307 * *$ & $169 * *$ & $394 * *$ & $313 * *$ & $152 * *$ & $172 * *$ \\
\hline Dyslexics-RL, Dyslexics-CA & - & 138 & -87 & - & 161 & $141^{* *}$ \\
\hline
\end{tabular}

** Significant effect $(p<.05)$

${ }^{a}$ The length effect is given by the slope of the linear regression

it did not interact with Group, we will present the results of the Anova with Group, Lexicality and Length as factors. This analysis revealed a triple interaction (Lexicality $\times$ Length $\times$ Group, $F[2,76]=4.88, p<.02$ ). Separate analysis for each group clarified that this triple interaction was due to the fact that in the chronological control group 2-syllable words were read extremely fast in comparison with nonwords of the same length and with longer words (in the chronological control group, for Lexicality $\times$ Length $F[2,48]=6.13, p<.01$; in the other groups, $F<1$; note however that even though the interaction was not significant, there is no evidence of a lexicality effect in the dyslexic group for the 3 -syllable items). In sum, the effect of length was significant in all three groups. Even though its magnitude appears to be greater for the dyslexic group than either of the controls (see the estimate of the length effect given by the slope of the linear regression in Table 5), it is only on the comparison with the chronological age controls that this difference reaches significance. So the efficiency of the decoding mechanism is reduced in the dyslexics in comparison with chronological controls, but there is no clear evidence that it is different from reading level controls.

Phonological awareness tasks

Table 6 shows the results for the detection of the syllable, phoneme and rime units in the two phonological tasks, same-different matching (an index of implicit awareness) and common unit identification (an index of explicit awareness), for the dyslexic group and for reading level controls (no results are available for chronological age controls). The results for the same-different task are presented as d' scores (Macmillan \& Creelman, 1991), an index of sensitivity that combines in a single measure the proportion of hits (correct detection of an event when it is present) with the proportion of false alarms (responding that an event is present when in fact it is not).

A repeated measures Anova with Group (Dyslexic versus Reading Level Controls) and Units (Syllable versus Phoneme versus Rime) as factors disclosed significant main effects of $\operatorname{Group}(F[1,40]=24.99, p<.001)$, Unit $(F[2,80]=22.38, p<.001)$, and the interaction between both $(F[2,80]=10.09, p<.001)$. The interaction was analysed with separate Anovas for each linguistic unit; these showed a significant 
Table 6 Mean accuracy for the dyslexic and reading level controls, in d' scores for the same-different task and in percent correct for the common unit task

** Significant effect $(p<.05)$

\begin{tabular}{llll}
\hline & Dyslexic & RL control & Dyslexic-RL \\
\hline Same-different (d') & & & \\
Syllable & 3.14 & 3.55 & $-0.4^{* *}$ \\
Phoneme & 3.22 & 3.65 & $-0.4^{* *}$ \\
Rime & 2.00 & 3.37 & $-1.4^{* *}$ \\
Common unit (\%) & & & \\
Syllable & 89.3 & 93.1 & -3.8 \\
Phoneme & 96.4 & 98.6 & -2.2 \\
Rime & 68.8 & 64.4 & 4.4 \\
\hline
\end{tabular}

difference between the dyslexics and the controls for the three units (syllable: $F[1,40]=5.28, p<.03$; phoneme: $F[1,40]=9.37, p<0.04$; rime: $F[1,40]=25.56$, $p<.001)$. The difference was more marked for the rime than for the syllable or phoneme, probably because the performance of the controls was close to ceiling for the syllable and phoneme.

At the explicit awareness level (common unit task), an Anova for repeated measures with Group and Unit as factors revealed an effect of Unit $(F[2,80]=38.04$, $p<.001)$, but no effect of Group or interaction $(F<1$ in each case). Performance was in general poorer for the rime than for the syllable or the initial phoneme, and this pattern was essentially the same in the dyslexic and control groups. Because the stimuli were disyllabic, and the task was to identify the critical segment in the first syllable, the correct identification of the rime involved being able to segment the first syllable from its neighbour and then doing subsyllabic segmentation into onset and rime. The most frequent error consisted of simplifying the rime by reducing it to its peak (for example, responding /u/ to the pair curva-furto, curve-theft).

Rapid naming of colors

In the rapid naming task, the dyslexic group named fewer colors (30) than the chronological controls $(35 ; F[1,38]=4.28, p<.05)$, but performed similarly to the reading level controls ( 29 colors named).

\section{Discussion and conclusion}

The results of this study showed that Portuguese dyslexic children read regular words more accurately than nonwords (10\% advantage) and irregular words $(46 \%$ advantage). Younger reading level controls (second and third graders) also showed a $10 \%$ advantage of words over nonwords, and a substantial, though not so marked, advantage of regular over irregular words $(25 \%)$. Older, chronological age controls (fourth graders) likewise were better at reading regular words than both nonwords and irregular words, although these advantages were smaller $(7 \%$ and $14 \%$ respectively). The RT results for the comparison of regular and irregular words closely match the accuracy results (the three groups responding more quickly to 
regular than irregular words), but the advantage of words over nonwords was significant only in the reading level controls. This is clear evidence of lexicality and regularity effects in the reading of Portuguese, both in dyslexic and non-dyslexic children, that are expressed in accuracy. The fact that Seymour et al. (2003) found reduced lexicality effects in Portuguese is probably due to the fact that in their crosslanguage study children were beginning readers at the first grade, and/or the stimuli were not difficult enough for differences to emerge. These results are also evidence that dyslexia in Portuguese manifests itself by low accuracy for nonword reading, as in English. This is quite different from what Wimmer et al. (2000) reported for German (reading performance of dyslexic children similar for words and nonwords). However, Ziegler, Perry, Ma-Wyatt, Ladner, and Schulte-Korne (2003) did find significant lexicality effects for both German and English dyslexic children.

We compared the magnitude of the lexicality effect in the dyslexic and control groups in order to establish whether there was a core decoding deficit. The advantage of words over nonwords indicated a significant difference between dyslexic children and the chronological age controls, but no difference between dyslexics and reading level controls. We conclude that the phonological decoding strategy was not subject to a developmental core deficit but instead to a developmental delay. This delay manifests itself in accuracy more robustly than in response times. It is important to mention that, differently from dyslexics learning to read in shallow orthographies, Portuguese dyslexics performed worse than controls in terms of accuracy, this result being more consistent with the results from opaque orthographies.

Another indicator of phonological decoding is the length effect. While Landerl et al. (1997) observed that the syllabic length effect was similar for dyslexic and control groups, Ziegler et al. (2003) found a much stronger effect of phonemic length among dyslexics than in any of the control groups. However, both studies present methodological issues that should be taken into account when reflecting on the results. Landerl et al. measured latencies by asking children to press a button when they felt they could read a target word. It is questionable whether this procedure constitutes an accurate measure of reading RTs. Also, in this study the English dyslexics had received remediation training, while the German ones had not (another difference was that the English dyslexics were selected on the basis of accuracy measures, and the German ones on reading speed). So, a direct comparison of the two cohorts based on these results is probably unwarranted. Ziegler et al. (2003) used stimuli with different syllabic structures, so that the longest words contained consonant clusters at the onset and/or coda position, while the shorter ones did not. The difference between dyslexics and controls was based on the analysis of the total pool of items even though there was evidence that length effects were weakened when items containing clusters were excluded. In our study, syllable types were maintained constant across lengths, thus making it possible to estimate the effect of length unconfounded by syllable complexity. We found that shorter words and nonwords were read faster than longer ones, especially bisyllables compared to trisyllables, by dyslexics as well as by younger reading level controls and same age non-dyslexic controls. In word reading, the magnitude of the length effect expressed by the linear regression slope was similar across groups. However, in nonwords it was significantly larger in the dyslexic group than in chronological age controls. This result suggests a specific fragility in 
sequential phonological decoding, as words can be read via lexical processes while nonwords cannot. Like the lexicality effect, the length effect had a bigger magnitude in dyslexic children than in the chronological controls, but was of the same order as that found in the reading level controls. This again implies a developmental delay rather than a core developmental deficit.

Concerning regularity, this study presents robust evidence, on reaction times and accuracy, of a superiority of regular word reading by Portuguese dyslexics, in comparison with controls. This pattern is similar to that described by Wimmer et al. (2000) and can be interpreted as an influence of the phonological deficit on the development of the orthographic lexicon. Since the difficulty in reading irregular words was larger for dyslexics than for reading level controls, this is evidence of a developmental deficit rather than a developmental delay. The difficulty in reading irregular words, and the relative advantage of regular words, was observed in almost all the dyslexic children (in 14 considering accuracy, and in 12 considering RTs). It is worth mentioning that this deviates from what has been observed in French studies (Genard et al., 1998; Sprenger-Charolles et al., 2000), where irregular word reading by dyslexics was roughly at the same level as reading controls while pseudoword reading was, for a subgroup of dyslexics, worse than reading level controls. In the present study, we did not find evidence of a subgroup of dyslexics for whom pseudoword reading (decoding) was the major difficulty; pseudoword reading by dyslexics and reading level controls was very similar. However, we studied a relatively small group of dyslexics and larger studies are needed before we can conclude on the issue of dyslexia subtypes in Portuguese. Interestingly, the impairment on the development of the orthographic lexicon appears to be milder in French than in Portuguese. Again, more research is needed in order to ascertain whether this difference results from psycholinguistic factors, from instructional practices that are carried out in the classroom or in specialized tuition, or both. Note that our 15 children were not receiving remediation tutoring, and we do not know if this was the case in the French studies cited.

In this study, then, dyslexic children exhibited a developmental delay in phonological development (see below), which had different consequences in the development of reading processes, a delay in decoding ability and a deficit in the orthographic lexicon.

\section{Phonological awareness and rapid naming}

Our results revealed deficits in both phonological awareness and rapid naming. However, while there was a difference between dyslexics and reading controls for the implicit phonological awareness, for rapid naming the difference was significant only relative to the chronological age controls. These results are in agreement with those reported by Cardoso-Martins and Pennington (2001) and Landerl et al. (1997), who propose that phonological awareness has stronger contributions to reading difficulties than rapid naming.

The difference between dyslexics and reading level controls was observed only in the implicit awareness (same-different judgement) task. We interpret this in terms of the complexity of the two tasks. In the same-different task, children were told that they 
would hear pairs of words, some of which shared sounds, and should indicate whether or not there were any shared sounds. After three training trials with corrective feedback, children were on their own to decide on the uncertainty. In the common unit task, children had already performed (though on different days/sessions) the samedifferent task, and they were asked to listen to pairs of words that were not entirely new, the positive pairs from the same/different task; they were told that the words shared a common sound or sounds that they were asked to pronounce aloud. Both tasks are demanding, as children must attend to two bisyllabic words with at least four phonemes each and maintain their phonological representations in working memory in order to identify the critical segment in the initial syllables of both words; but in the common unit task the children already know that there is a common sound and so they may be more prone to invest effort in locating it (rather than doing so in the samedifferent task where the common element is present only in half of the trials). So, the difference between the two tasks may be motivational or strategic. Alternatively, it may be that making a same-different judgement about sounds is in itself a difficult task for dyslexic children. Furthermore, being asked to identify a segment is probably a more familiar task to the children because it is more akin to school exercises than making a same/different judgement. In either case, the present results are evidence of a developmental deficit in implicit phonological awareness which may be the core competence from which reading and explicit phonological awareness evolve.

The implicit awareness difference between the dyslexic children and the reading controls was significant for the three units but more marked for the rime (about .34 less sensitivity than the control group) than for the syllable or the phoneme (.10 difference). In the common unit task, the rime was also the least accessible unit, with performance about equivalent for the syllable and the phoneme, and this outcome was the same in the dyslexic and reading level control groups. This shows the inherent difficulty of sub-syllabic segmentation, both for normal readers and for dyslexics.

In summary, we argue that Portuguese dyslexic children demonstrate a deficit in implicit phonological awareness and in orthographic processing, accompanied by a developmental delay in decoding ability (as shown by the lexicality and length effects) and explicit phonological awareness. How does this pattern fit into the shallow-opaque dimension? The typical pattern of dyslexia in opaque orthographies is a decoding deficit (expressed both on accuracy and reaction times) that affects regular word and nonword reading. Differently, dyslexia in shallow orthographies is characterized by dysfluency (longer reaction times, not worse accuracy), and reduced or absent lexicality and regularity effects. Our results indicate a specific, intermediate pattern. Consistent with results from research of dyslexia in shallow orthographies, dyslexia in Portuguese does not preclude the development of decoding abilities at the level of normal beginning readers (nonword reading is not significantly different from reading level controls). However, the development of the orthographic lexicon, essential for reading in an orthography of intermediate depth, is impaired. Thus, the expression of dyslexia in Portuguese departs from what is typical of dyslexia in shallow orthographies. The lexicality effect was stronger for dyslexics than for chronological age controls, both in accuracy and reaction time, a result that is in accordance with the findings from opaque orthographies. Furthermore, the regularity effect was larger in dyslexics than in reading level controls. At the same time, and as 
has been found both for opaque and for shallow orthographies, difficulties in phonological awareness were also characteristic of dyslexia in Portuguese.

Acknowledgements We thank Sylvia Defior, Jacqueline Leybaert, and Francisca Serrano for enlightening discussions, and two anonymous reviewers for their comments on earlier versions of the manuscript. This study was supported by the Portuguese Foundation for Science and Technology through a grant to the Language Group of the Center for Psychology at the University of Porto and a doctoral fellowship to Ana Sucena.

\section{Appendix}

Stimuli for common unit identification (Panel A) and same/different judgement (Panel B)

\begin{tabular}{|c|c|c|c|c|c|c|c|c|c|c|}
\hline \multirow{2}{*}{$\frac{\text { Syllable type }}{\text { Panel } \mathrm{A}^{\mathrm{a}}}$} & \multirow[t]{2}{*}{$\#$} & \multicolumn{3}{|c|}{ Common Syllable } & \multicolumn{3}{|c|}{ Common Phoneme } & \multicolumn{3}{|c|}{ Common Rime } \\
\hline & & & & & & & & & & \\
\hline $\mathrm{CV}$ & 1 & vinda & vinco & vĩ & baba & beco & $\mathrm{b}$ & fuga & lume & $\mathrm{u}$ \\
\hline $\mathrm{CV}$ & 2 & rude & rumo & $\mathrm{ru}$ & caco & cola & $\mathrm{k}$ & lama & cano & $\alpha$ \\
\hline $\mathrm{CV}$ & 3 & povo & poça & po & dedo & dica & $\mathrm{d}$ & mito & vira & $\mathrm{i}$ \\
\hline $\mathrm{CV}$ & 4 & pêlo & pêra & pe & fera & figo & $\mathrm{f}$ & toga & colo & ó \\
\hline CVC & 5 & balça & balde & bal & mosca & março & $\mathrm{m}$ & silva & filme & il \\
\hline CVC & 6 & cisco & cisne & sis & perna & polvo & $\mathrm{p}$ & bolso & polpa & ol \\
\hline $\mathrm{CVC}$ & 7 & larva & largo & lar & relva & risco & $\mathrm{r}$ & bosque & costa & oS \\
\hline CVC & 8 & melga & melro & mel & sarda & silvo & s & curva & furto & ur \\
\hline \multicolumn{11}{|l|}{ Training pairs } \\
\hline $\mathrm{CV}$ & & bago & bala & ba & casa & colo & $\mathrm{k}$ & cave & dado & $\mathrm{a}$ \\
\hline $\mathrm{CV}$ & & dona & dote & do & gato & gula & $\mathrm{g}$ & fome & gola & o \\
\hline CVC & & burgo & burla & bur & caldo & curva & $\mathrm{k}$ & marca & pardo & ar \\
\hline \multicolumn{11}{|l|}{ Panel $\mathrm{B}^{\mathrm{b}}$} \\
\hline $\mathrm{CV}$ & 1 & tosse & vaso & & peru & bica & & baba & giro & \\
\hline $\mathrm{CV}$ & 2 & depor & final & & sofá & bebé & & golo & mata & \\
\hline $\mathrm{CV}$ & 3 & gelo & vaca & & bolor & legal & & papa & ruço & \\
\hline $\mathrm{CV}$ & 4 & vento & bala & & doce & fava & & sala & tinto & \\
\hline $\mathrm{CVC}$ & 5 & xisto & belga & & melga & pisco & & bispo & cerca & \\
\hline CVC & 6 & barco & culpa & & porco & relva & & cesto & farda & \\
\hline CVC & 7 & testa & vulto & & rosto & salsa & & festa & março & \\
\hline $\mathrm{CVC}$ & 8 & filme & larva & & selva & tarde & & lesma & bolso & \\
\hline \multicolumn{11}{|l|}{ Training pairs } \\
\hline $\mathrm{CV}$ & & laca & mimo & & fera & gomo & & chefe & barro & \\
\hline $\mathrm{CV}$ & & mola & pico & & guita & judo & & cola & dente & \\
\hline CVC & & surdo & vespa & & melro & parque & & guelra & largo & \\
\hline
\end{tabular}

In each task, three linguistic units are tested: Syllable, Phoneme and Rime

${ }^{\mathrm{a}}$ There are eight word pairs per condition, plus three for training

${ }^{\mathrm{b}}$ Stimuli are the same as in Panel A for pairs that share one segment in the first syllable (same condition), plus the 8 pairs presented here for pairs that have no common unit (different condition) 


\section{References}

Bacelar do Nascimento, M. F., Casteleiro, J. M., Marques, M. L. G., Barreto, F., Amaro, R., \& Veloso, R. (2005). Corlex: Léxico multifuncional computorizado do Português contemporâneo [lmcpc_dec. txt]. Available from Centro de Linguística da Universidade de Lisboa Web site: http://www.clul. ul.pt/sectores/linguistica_de_corpus/projecto_lmcpc.php.

Bowers, P., \& Wolf, M. (1993). Theoretical links among naming speed, precise timing mechanisms and orthographic skills in dyslexia. Reading and Writing: An Interdisciplinary Journal, 5, 69-85.

Cardoso-Martins, C., \& Pennington, B. (2001). Qual é a contribuição da nomeação seriada rápida para a habilidade de leitura e escrita? Evidência de crianças e adolescentes com e sem dificuldades de leitura. Psicologia: Reflexão e Crítica, 14(2), 387-397.

Coltheart, M., Masterson, J., Byng, S., Prior, M., \& Riddoch, J. (1983). Surface dyslexia. Quarterly Journal of Experimental Psychology, 35(A), 469-495.

Denckla, M., \& Rudel, R. (1976). 'Rapid automatised naming': Dyslexia differentiated from other learning disabilities. Neuropsychologia, 14, 471-479.

Duncan, L., Seymour, P., \& Hill, S. (1997). How important are rhyme and analogy in beginning reading? Cognition, 63, 171-208.

Evans, H. M., \& Seymour, P. H. K. (1997). Genetic constraints on the development of alphabetic literacy: A cognitive study of two 48, XXXY cases. Cognitive Neuropsychology, 14, 255-291.

Fernandes, S., Ventura, P., Querido, L., \& Morais, J. (2007). Reading and spelling acquisition in European Portuguese: A preliminary study. Reading \& Writing. doi:10.1007/s11145-007-9093-7.

Frith, U. (1985). Beneath the surface of developmental dyslexia. In K. E. Patterson, J. C. Marshall, \& M. Coltheart (Eds.), Surface dyslexia-neuropsychological and cognitive studies of phonological reading (pp. 301-330). London: Lawrence Erlbaum Associates.

Frost, R., Katz, L., \& Bentin, S. (1987). Strategies for visual word recognition and orthographical depth: A multilingual comparison. Journal of Experimental Psychology: Human Perception and Performance, 13(1), 104-115.

Genard, N., Mousty, P., Alegria, J., Leybaert, J., \& Morais, J. (1998). Methods to establish subtypes of developmental dyslexia. In P. Reitsma \& L. Verhoeven (Eds.), Problems and interventions in literacy development (pp. 163-176). The Netherlands: Kluwer Academic Publishers.

Gomes, I. (2001). Ler e escrever em português europeu (Vols. 1-2) (Reading and writing in European Portuguese). Unpublished doctoral dissertation, Universidade do Porto, Portugal.

Gomes, I., \& Castro, S. L. (2003). Porlex, a lexical database in European Portuguese. Psychologica, 32, 91-108.

Harm, M. W., \& Seidenberg, M. S. (1999). Phonology, reading and dyslexia: Insights from connectionist models. Psychological Review, 106, 491-528.

Katz, L., \& Frost, R. (1992). Reading in different ortographies: The orthographic depth hypothesis. In L. Frost (Ed.), Orthography, phonology, morphology, and meaning. Amsterdam: North-Holland.

Landerl, K., Wimmer, H., \& Frith, U. (1997). The impact of orthographic consistency on dyslexia: A German-English comparison. Cognition, 63, 315-334.

Lobrot, M. (1973). Lire avec épreuves pour évaluer la capacité de lecture. Paris: ESF.

Lyytinen, H., Erskine, J., Tolvanen, A., Torppa, M., Poikkeus, A., \& Lyytinen, P. (2006). Trajectories of reading development: A follow-up from birth to school age of children with and without risk for dyslexia. Merrill-Palmer Quarterly, 52, 514-546.

Macmillan, N. A., \& Creelman, C. D. (1991). Detection theory: A user's guide. Cambridge, MA: Cambridge University Press.

Manis, F., Seidenberg, M., Doi, L., McBride-Chang, C., \& Peterson, A. (1996). On the basis of two subtypes of developmental dyslexia. Cognition, 58, 157-195.

Rack, J., Snowling, M., \& Olson, R. (1992). The nonword reading deficit in developmental dyslexia: A review. Reading Research Quarterly, 27, 29-53.

Seymour, P. H. K., Aro, M., \& Erskine, J. (2003). Foundation literacy acquisition in European orthographies. British Journal of Psychology, 94, 143-174.

Seymour, P. H. K., \& Bunce, F. (1994). Application of cognitive models to remediation in cases of developmental dyslexia. In M. J. Riddoch \& G. W. Humphreys (Eds.), Cognitive neuropsychology and cognitive rehabilitation. Hove: LEA. 
Seymour, P. H. K., \& Evans, H. M. (1999). Foundation-level dyslexias: Assessment and treatment. Journal of Learning Disabilities, 32, 394-405.

Seymour, P. H. K., \& McGregor, C. J. (1984). Developmental dyslexia: A cognitive experimental analysis of phonological, morphemic and visual impairments. Cognitive Neuropsychology, 1, 43-82.

Share, D. (1995). Phonological recoding and self-teaching: sine qua non of reading acquisition. Cognition, 55, 151-218.

Share, D. (1999). Phonological recoding and orthographic learning: A direct test of the self-teaching hypothesis. Journal of Experimental Child Psychology, 72, 95-129.

Simões, M. R. (2000). Investigações no âmbito da aferição nacional do teste das Matrizes Progressivas Coloridas de Raven (M.P.C.R) (Studies for the national standardization of the Raven Progressive Coloured Matrices). Lisboa: Fundação Calouste Gulbenkian/Fundação para a Ciência e a Tecnologia.

Snowling, M. (2000). Dyslexia (2nd ed.). London: Blackwell Publishers.

Sprenger-Charolles, L., Colé, P., Béchennec, D., \& Kipffer-Piquard, A. (2006). French normative data on reading and related skills from EVALEC, a new computerized battery of tests (end Grade 1, Grade 2, Grade 3, and Grade 4). Revue européenne de psychologie appliquée, 55, 157-186.

Sprenger-Charolles, L., Colé, P., Lacert, P., \& Serniclaes, W. (2000). On subtypes of developmental dyslexia: Evidence from processing time and accuracy scores. Canadian Journal of Experimental Psychology, 54, 87-103.

Stanovich, K., Siegel, L., \& Gottardo, A. (1997). Converging evidence for phonological and surface subtypes of reading disability. Journal of Educational Psychology, 89, 114-127.

Sucena, A., \& Castro, S. L. (2008). Aprender a ler e avaliar a leitura (Learning how to read and the assessment of reading). Coimbra: Almedina.

Treiman, R., \& Zukowski, A. (1991). Levels of phonological awareness. In S. A. Brady \& D. P. Shankweiler (Eds.), Phonological processes in literacy: A tribute to Isabelle Y. Liberman (pp. 37-45). Hillsdale, NJ: Lawrence Erlbaum.

Vellutino, F. R., Scanlon, D. M., \& Spearing, D. (1995). Semantic and phonological coding in poor and normal readers. Journal of Experimental Child Psychology, 59, 76-123.

Vigário, M., \& Falé, I. (1994). A sílaba no português fundamental: Uma descrição e algumas considerações de ordem teórica (The syllable in Portuguese: Description and theoretical considerations). In Associação Portuguesa de Linguística (Ed.), Actas do IX Encontro da Associação Portuguesa de Linguística (pp. 465-478). Lisboa: Colibri, Artes Gráficas.

Wagner, R., \& Torgesen, J. (1987). The nature of phonological processing and its causal role in the acquisition of reading skills. Psychological Bulletin, 101, 192-212.

Wimmer, H. (1993). Characteristics of developmental dyslexia in a regular writing system. Applied Psycholinguistics, 14, 1-33.

Wimmer, H. (1996). The nonword reading deficit in developmental dyslexia: Evidence from children learning to read German. Journal of Experimental Child Psychology, 61, 80-90.

Wimmer, H., Mayringer, H., \& Landerl, K. (2000). The double-deficit hypothesis and difficulties in learning to read a regular orthography. Journal of Educational Psychology, 92, 668-680.

Wolf, M., Bally, H., \& Morris, R. (1986). Automaticity, retrieval processes, and reading: A longitudinal study in average and impaired readers. Child Development, 57, 988-1000.

Yap, R., \& van der Leij, A. (1993). Word Processing in dyslexics: An automatic decoding deficit? Reading and Writing: An Interdisciplinary Journal, 5, 261-279.

Ziegler, J., \& Goswami, U. (2005). Reading acquisition, developmental dyslexia and skilled reading across languages: A psycholinguistic grain size theory. Psychological Bulletin, 13(1), 3-29.

Ziegler, J., Perry, C., Ma-Wyatt, A., Ladner, D., \& Schulte-Korne, G. (2003). Developmental dyslexia in different languages: Language-specific or universal? Journal of Experimental Child Language, 86, 169-193.

Zoccoloti, P., Luca, M., Pace, E., Judica, A., Orlandi, M., \& Spinelli, D. (1999). Markers of developmental surface dyslexia in a language (Italian) with high grapheme-phoneme correspondence. Applied Psycholinguistics, 20, 191-216.

Zorzi, M., Houghton, G., \& Butterworth, B. (1998). Two routes or one in reading aloud? A connectionist dual process model. Journal of Experimental Psychology: Human Perception and Performance, 24, 1131-1161. 